\title{
Real-time Monitoring of Biomass Temperature and Humidity Based on the Internet of Things
}

\author{
Aryanto $^{1}$ Melvi $^{1}$ Ardian Ulvan ${ }^{1, *}$ \\ ${ }^{1}$ Department of Electrical Engineering, Universitas Lampung, Bandar Lampung, Indonesia, \\ *Corresponding author. Email: ardian.ulvan@eng.unila.ac.id
}

\begin{abstract}
The conversion of biomass to energy is known as biomass regeneration. This energy is used to generate electricity and heat. Combustion systems and classification systems are a major category of biomass conversion technology for power and heat production. The temperature in the biomass gasifier plays an important role in producing gas with high calorific value. Temperature can be measured correctly without error and can then be monitored and controlled by the Internet of Things. In this work, various experimental studies were carried out on variations in temperature with changes in the airflow rate. To measure the temperature profile inside the gasifier, DHT22 and NTC (Negative Temperature Coefficient) thermocouple with the selected data acquisition device. From the results of data acquisition using IoT, precision data, and real-time temperature of biomass gasification were obtained using the Wemos D1 device.
\end{abstract}

Keywords: data acquisition, Internet of Things, temperature of biomass, biomass gasifier, Wemos D1

\section{INTRODUCTION}

Weather is a physical state of the atmosphere at a certain time somewhere. The weather can change in a short time such as humidity, temperature, air, and wind direction. Information on average weather conditions covering a long period is a statistical opportunity to determine climate. Climate has an important role in the life of living things on earth. Differences in climatic and weather conditions in various countries on earth are due to several factors that control climate, namely the position of latitude, the presence of oceans or other water surfaces, the pattern of wind direction, the appearance of the earth's land surface, density and types of vegetation [1].

The available energy sources in Indonesia, aside from petroleum, still have a lot of potentials to be extracted and used in the form of renewable energy sources. Gasification is a thermal process, where heating of biomass in low oxygen environment converts solid biomass or other carbonaceous solids into flammable synthetic gases. Through the gasification process, we can turn all organic material into clean, neutral fuel gas and the best way to utilize biomass gasification using electricity or heat fuel.
Changing weather often results in changes in the process of gasification of biomass quickly [2]. This unpredictable change causes the chemical change to not optimal thermal energy in the biomass. So, we need the development of a system that can do weather measurements, precision and can be accessed by the public through the Android device. This measured information is expected to monitor the gasification process in biomass. This system can be built using the Wemos D1 microcontroller Internet of Things (IoT) in it with the use of temperature and humidity sensors. The use of the Wemos D1 microcontroller with the IoT system simultaneously at the climatology station can make weather information obtained easily and in realtime because it is connected directly to the internet. The application of IoT technology to weather gauges automatically can provide effective and efficient information. The use of sensors as a measuring tool that is connected to the Wemos D1 microcontroller will get more accurate data that is useful, especially in the field of biomass. Therefore, this research has been carried out to create a programming algorithm to predict the results of gasification from temperature sensor and humidity sensor monitoring data in real-time using the Wemos D1 microcontroller. 


\section{LITERATURE REVIEW}

\subsection{Biomass Gasification and Temperature}

Biomass is a biological material derived from plants, animals, including humans, which can be used as an energy source [3-7]. Type materials that can be read as biomass vary greatly from agricultural residues, animal residues, wood chips, wood produced from urban residues dried and contaminated with other ingredients, to organic matter from garbage densely populated in urban areas. Biomass can be used to produce energy one of them through a thermochemical process for example pyrolysis, gasification, and burning. Gasification can be interpreted in a language as gas making [8]. The schematic process of Biomass gasification is depicted in Figure 1.

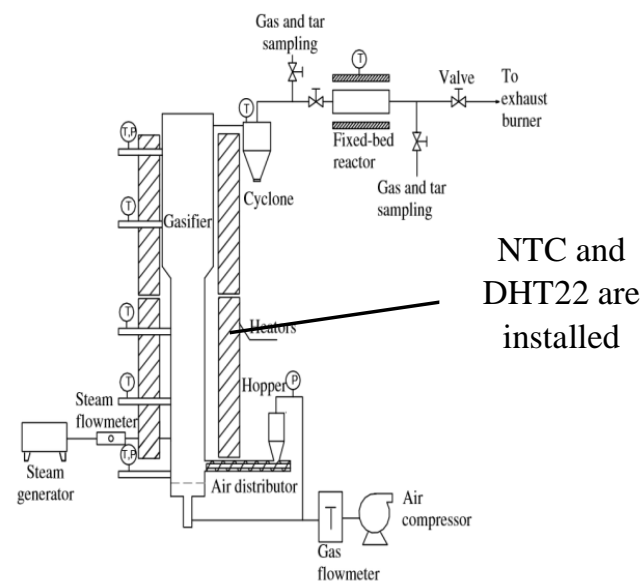

Figure 1. Schematic Diagram of Biomass Catalytic Gasification

\subsection{Internet of Things Wemos D1 Boards}

Wemos D1 version is a development from version 0.9. and in version 1.0, the ESP8266 type (see Figure 2) is used as the microcontroller which is considered more stable than ESP-12. Also, the module board size is reduced so that it is compatible to be used on making project prototypes on the breadboard. Moreover, there are special pins for SPI (Serial Peripheral Interface) and PWM (Pulse Width Modulation) communications that are not available in version 0.9 [9].

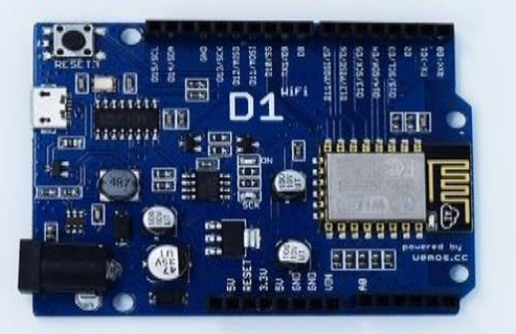

Figure 2 WEMOS ESP8266

\section{METHOD}

The IoT is an idea where all objects in the real world can communicate with each other as part of an integrated system using the internet network as a link. For example, CCTV installed along the road is connected to an internet connection and put together in a control room which may be tens of kilometers away. Or a smart home that can be managed via a smartphone with the help of an internet connection. The IoT device consists of a sensor as a data collection medium, an internet connection as a communication medium, and a server as a collector of information received by the sensor and for analysis [10-14].

The initial idea of the Internet of Things was first raised by Kevin Ashton in 1999 in one of his presentations. Now many large companies have begun to explore the Internet of Things, just call Intel, Microsoft, Oracle, and many others. Many predict that the influence of the Internet of Things is "the next big thing" in the world of information technology, this is because IoT offers a lot of potentials that can be explored. A simple example of the benefits and implementation of the Internet of Things, for example, is a refrigerator that can notify its owner via SMS or email about any food and drinks that have run out and must be stocked again [15].

The devices and equipment used in this experiment are shown in Table 1.

Table 1. Devices and Equipment

\begin{tabular}{|l|l|l|}
\hline No & \multicolumn{1}{|c|}{$\begin{array}{c}\text { Devices and } \\
\text { Equipment }\end{array}$} & \multicolumn{1}{c|}{ Usability Function } \\
\hline 1 & Wemos D1 & $\begin{array}{l}\text { Internet of Things Boards } \\
\text { To read temperature and } \\
\text { humidity } \\
\text { DHT22 and NTC }\end{array}$ \\
3 & Power Supply & $\begin{array}{l}\text { To supply energy to the } \\
\text { prototype } \\
\text { To connect each } \\
\text { component }\end{array}$ \\
\hline
\end{tabular}

For an illustration of the cable connection, Wemos D1 to the sensor can be seen in Figure 3. The sensor is mounted on a gasification wall on the biomass. Then Wemos d1 will send the temperature and humidity data obtained from DHT22 and NTC to the internet.

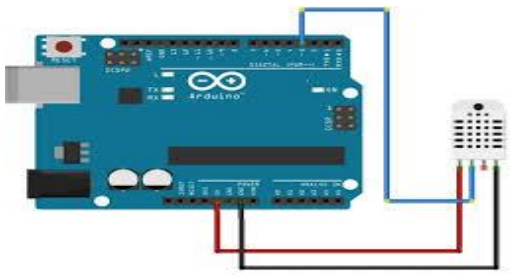

Figure 3 Cable Connection from Wemos D1 to Sensor 
Figure 4 is depicted the flow of data communication using IoT with Thingspeak cloud server which is easy and relatively cheaper:
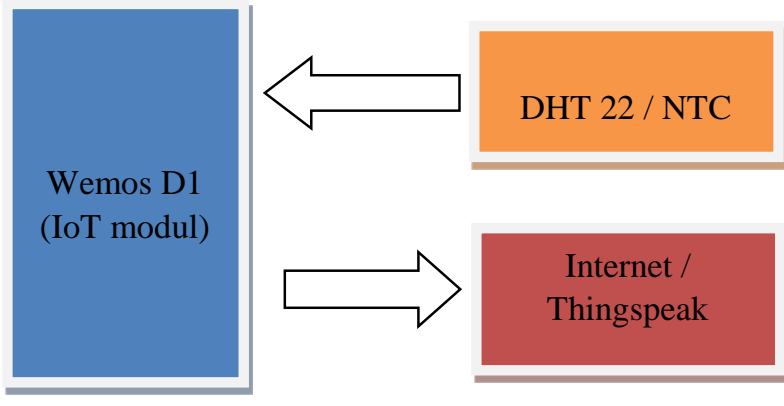

Figure 4 The flow of data communication

Figure 5 shows a display of the IoT tools and DHT22 sensors that have been made, the DHT22 sensor is calibrated at room temperature:

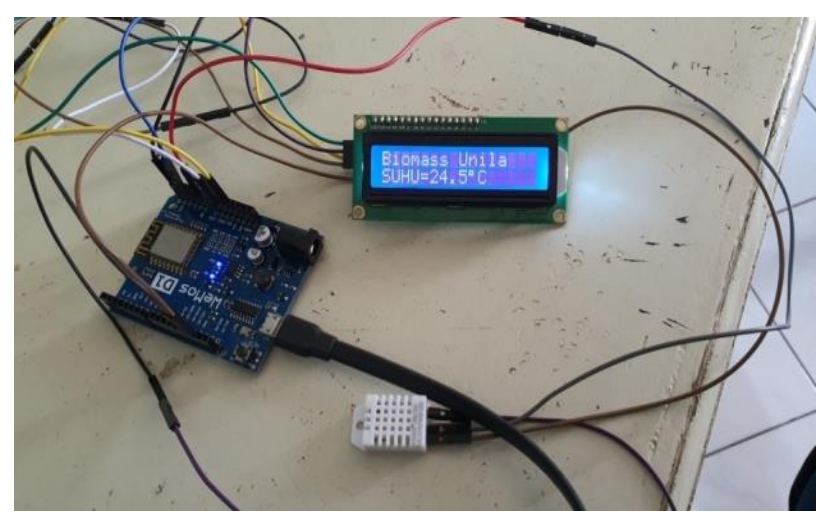

Figure 5 A complete sensor devices and the IoT

\section{RESULT AND DISCUSSION}

Table 2 shows the comparison between the proposed system (IoT) and the existing for the airflow rate of 120 lpm:

Table 2. Comparison Between Proposed System (IoT) and Existing

\begin{tabular}{|c|c|c|c|}
\hline Created_at & $\begin{array}{c}\text { Field-1 } \\
\left(\text { NTC, }{ }^{\circ} \text { C) }\right.\end{array}$ & $\begin{array}{c}\text { Field-2 } \\
\left(\text { DHT22, }{ }^{\circ} \text { C) }\right.\end{array}$ & $\begin{array}{c}\text { Temperature } \\
\text { of existing } \\
\text { system }\left({ }^{\circ} \mathbf{C}\right)\end{array}$ \\
\hline $\begin{array}{c}\text { 2020-08-02 } \\
\text { 07:15:51 UTC }\end{array}$ & 202,201 & 202,201 & 200.00 \\
\hline $\begin{array}{c}\text { 2020-08-02 } \\
\text { 07:19:58 UTC }\end{array}$ & 202,001 & 202,001 & 199.00 \\
\hline $\begin{array}{c}2020-08-02 \\
07: 21: 31 \text { UTC }\end{array}$ & 200.21 & 200.21 & 200.00 \\
\hline $\begin{array}{c}2020-08-02 \\
07: 23: 08 \text { UTC }\end{array}$ & 202,201 & 202,201 & 199.67 \\
\hline $\begin{array}{c}2020-08-02 \\
09: 37: 51 \text { UTC }\end{array}$ & 202,001 & 202,001 & 199.67 \\
\hline
\end{tabular}

\begin{tabular}{|c|c|c|c|}
\hline $\begin{array}{c}2020-08-02 \\
09: 38: 57 \text { UTC }\end{array}$ & 200.21 & 200.21 & 199.67 \\
\hline $\begin{array}{c}2020-08-02 \\
09: 42: 22 \text { UTC }\end{array}$ & 202,201 & 202,201 & 199.67 \\
\hline $\begin{array}{c}2020-08-02 \\
09: 44: 38 \text { UTC }\end{array}$ & 202,001 & 202,001 & 199.67 \\
\hline $\begin{array}{c}2020-08-02 \\
09: 52: 21 \text { UTC }\end{array}$ & 200.21 & 200.21 & 199.67 \\
\hline $\begin{array}{c}2020-08-02 \\
09: 52: 43 \text { UTC }\end{array}$ & 202,201 & 202,201 & 199.67 \\
\hline $\begin{array}{c}2020-08-02 \\
09: 57: 28 \text { UTC }\end{array}$ & 202,001 & 202,001 & 199.67 \\
\hline $\begin{array}{c}2020-08-02 \\
10: 01: 14 \text { UTC }\end{array}$ & 198,59 & 198,59 & 199.67 \\
\hline $\begin{array}{c}2020-08-02 \\
10: 06: 26 \text { UTC }\end{array}$ & 202,201 & 202,201 & 199.67 \\
\hline $\begin{array}{c}2020-08-02 \\
10: 15: 11 \text { UTC }\end{array}$ & 202,001 & 202,001 & 199.67 \\
\hline $\begin{array}{c}2020-08-02 \\
10: 25: 43 \text { UTC }\end{array}$ & 200.21 & 200.21 & 199.67 \\
\hline $\begin{array}{c}2020-08-02 \\
19: 34: 35 \text { UTC }\end{array}$ & 202,201 & 202,201 & 199.67 \\
\hline $\begin{array}{c}2020-08-02 \\
19: 35: 07 \text { UTC }\end{array}$ & 202,001 & 202,001 & 199.67 \\
\hline $\begin{array}{c}2020-08-02 \\
22: 27: 40 \text { UTC }\end{array}$ & 200.21 & 200.21 & 199.67 \\
\hline $\begin{array}{c}2020-08-02 \\
22: 28: 08 \text { UTC }\end{array}$ & 202,201 & 202,201 & 199.67 \\
\hline $\begin{array}{c}2020-08-03 \\
00: 43: 20 \text { UTC }\end{array}$ & 202,001 & 202,001 & 199.67 \\
\hline $\begin{array}{c}2020-08-03 \\
01: 45: 20 \text { UTC }\end{array}$ & 200.21 & 200.21 & 199.67 \\
\hline $\begin{array}{c}2020-08-03 \\
01: 45: 40 \text { UTC }\end{array}$ & 202,201 & 202,201 & 199.67 \\
\hline $\begin{array}{c}2020-08-03 \\
01: 46: 59 \text { UTC }\end{array}$ & 202,001 & 202,001 & 199.67 \\
\hline $\begin{array}{c}2020-08-03 \\
01: 50: 10 \text { UTC }\end{array}$ & 198,59 & 198,59 & 199.67 \\
\hline $\begin{array}{c}2020-08-03 \\
02: 04: 31 \text { UTC }\end{array}$ & 202,201 & 202,201 & 199.67 \\
\hline $\begin{array}{c}2020-08-03 \\
02: 17: 27 \text { UTC }\end{array}$ & 202,001 & 202,001 & 199.67 \\
\hline $\begin{array}{c}2020-08-03 \\
02: 25: 28 \text { UTC }\end{array}$ & 200.21 & 200.21 & 199.67 \\
\hline
\end{tabular}

The gasifier steady-state temperature is reported in Table 2 using the measured measurements and the proposed measurement settings. Experiments were carried out with different air flow rates and steady-state temperatures according to demand. It is seen that measurement is an accurate measurement module that exists. Based on experimental data for the airflow rate of $120 \mathrm{lpm}$ the actual temperature in the drying zone is $201^{\circ} \mathrm{C}$, the proposed system (IoT) temperature is $202^{\circ} \mathrm{C}$, and the existing system temperature is $200^{\circ} \mathrm{C}$. Hence an accurate measurement is more accurate.

\section{CONCLUSION}

Experiments were carried out to study the temperature profile of biomass in various zones in the gasifier using IoT-based Wemos D1. The temperature change during gasification affects the overall performance of the classification system. It has been 
observed that the proposed measurement system provides a more precise guarantee of the existing measurement measurements. The measurement module has been developed using the NTC temperature sensor and is calibrated according to standards so that it can provide accurate measurements. Six different flow rates were applied to the gasifier to study the steady-state temperature profile. From the experimental data, it is known that the airflow rate is $120 \mathrm{lpm}$, the actual temperature in the drying zone is 201 , the proposed system temperature is $202{ }^{\circ} \mathrm{C}$ and the existing system temperature is $200{ }^{\circ} \mathrm{C}$. Compared to the existing system, the proposed measurement is more accurate because it uses the help of the IoT real-time recording system.

\section{REFERENCES}

[1] S. Sippel, et.al., 2020, Climate change now detectable from any single day of weather at global scale. Nature Climate Change, 10.1: 35-41.

[2] B. Chaitanya, A.D. Thakur, R. Raj, 2020, Biomass Gasifier-Powered Adsorption Chiller for Atmospheric Water Harvesting: Prospects in Developing World. In: Advances in Energy Research, Vol. 1. Springer, Singapore. p. 451-460.

[3] R.N. Singh, U. Jena, J.B. Patel, A.M. Sharma, 2006. Feasibility study of cashew nut shells as an open core gasifier feedstock. Renewable Energy, 31: 481-487. DOI: 10.1016/j.renene.2005.04.010.

[4] Z.A. Zainal, R. Ali, C.H. Lean, K.N. Seetharamu, 2001. Prediction of performance of a downdraft gasifier using equilibrium modeling for different biomass materials. Energy Conversion Manage. 42: 1499-1515. DOI: 10.1016/S01968904(00)00078-9.

[5] J. R. Bunt, F. B. Waanders, "Identification of the reaction zones occurring in a commercial-scale Sasol-Lurgi FBDB gasifier," Fuel, vol. 87, nos. 10-11, pp. 1814-1823, Aug. 2008.

[6] M.N.Z. Moni, S.A. Sulaiman, 2013. Downdraft Gasification of Oil Palm Frond: Effects of Temperature and Operation Time. Asian Journal of Scientific Research, 6: 197-206

[7] C. Erlich, T.H. Fransson, 2011. Downdraft gasification of pellets made of wood, palm-oil residues respective bagasse: Experimental study. Applied Energy, 88: 899-908. DOI: 10.1016/j.apenergy.2010.08.028
[8] W.B. Wincy, M. Edwin, S.J. Shekar, 2020, Energy and exergy evaluation of rice processing mills working with biomass gasifier in parboiling process. Fuel, 2020, 259: 116255.

[9] F. Tahir, W. Ridwan, I.Z. Nasibu, 2020, Monitor Kualitas Udara Berbasis Web Menggunakan Raspberry Pi dan Modul Wemos D1. Jurnal Teknik, 18.1: 35-44.

[10] K.A. Al-attab, Z.A. Zainal, 2011, Design and performance of a pressurized cyclone combustor (PCC) for high and low heating value gas combustion, Applied Energy, 88 (4), pp. 10841095.

[11] G. Xu, et al., 2006, The superior technical choice for a dual fluidized bed gasification, Ind. Eng. Chem. Res. 45.

[12] P.N. Sheth, B.V. Babu, 2009b. Experimental studies on producer gas generation from wood waste in a downdraft biomass Gasifier. Bioresource Technology,100, 3127-3133.

[13] P. Mondal P, G.S. Dang, M.O. Garg, 2011, Syngas production through gasification and cleanup for downstream applications and recent developments. Fuel Process Technology 2011; 92:1395e410.

[14] L. Pengmei, W. Chuangzhi, M. Longlong, Z. Yuan, 2008. A study on the economic efficiency of hydrogen production from biomass residues in China. Renewable Energy, 33: 1874-1879. DOI: 10.1016/j.renene.2007.11.002.

[15] Y. Qadri, A. Yazdan, et.al., 2020, The Future of Healthcare Internet of Things: A Survey of Emerging Technologies. IEEE Communications Surveys \& Tutorials, 2020, 22.2: 1121-1167.

[16] U. Henriksen, J. Ahrenfeldt, T.K. Jensen, B. Gøbel, J.B. Bentzen, C. Hindsgaul, L.H. Sørensen, 2006, The design, construction and operation of a 75 kW Two-Stage gasifier, Energy 31 (10e11), $1542 \mathrm{e} 1553$. 